\title{
A novel simple method for measuring the velocity of dam-break flow
}

\author{
P. B. Adegoke, W. Atherton \& R. M. Al Khaddar \\ Built Environment, Liverpool John Moores University, UK
}

\begin{abstract}
The study of dam-break waves (DBW) is extremely important in providing the information needed for risk assessment and management of coastal and riverine areas. Adequate and acceptable preparedness for such an event to allow mitigation of adverse impacts requires modelling of the flood as well as accurate estimation of potential flood depths, flow velocities, and timing of the flood arrival. This study investigated the effect of floodwater waves on various wall surfaces and wall slopes in a $4.7 \mathrm{~m}$ long wave tank by modelling a dam-break phenomenon. The paper reports the novel simple methods (the Imaging System (IS) and the sensor Signal Capture (SSC) technique) used for the estimation of wave front propagation velocity which are the adaptations of the commonly used Particle Image Velocimetry (PIV). The two techniques demonstrated good agreement with the dam break wave theory as well as agreement between each other. However, the SSC method with wave probes at a shorter separation distance $(0.41 \mathrm{~m}$ apart) appears better and more in line with the results obtained by previous investigators. The development represents a useful laboratory scheme that is well suited for educational and initial research studies. Keywords: dam-break, flow velocity, particle image velocimetry, flood waves.
\end{abstract}

\section{Introduction}

The concept of traditional flood protection is increasingly being replaced by comprehensive risk management, which includes structural and non-structural measures [1]. Hazard and risk maps are of particular importance for planning purposes, risk awareness campaigns and the encouragement of private preventive measures. Flood hazard risks are characterised by flood impact parameters such as water depth and flow velocity. However, there has been a strong focus on 
inundation depth as the main determinant for flood damage probably due to limited information about other parameters characterising the flood, e.g. flow velocity.

A systematic review of flood impacts on buildings and structures by Kelman and Spence [2] revealed various damage mechanisms including hydrodynamic actions related to waves and velocity as a result of turbulence. Dam-breaks have been known for destroying buildings and infrastructures and also being responsible for numerous losses of life in coastal and riverine areas. They generally result in flash flood runoff in rivers and streams, debris flow surges and tsunami run-up on dry coastal plains. In all these cases, the surge front is a sudden discontinuity characterized by extremely rapid variations of flow depth and velocity.

Flow velocity is generally presumed to influence flood damage. According to Kreibich et al. [3] a significant influence of flow velocity on structural damage could be shown in contrast to a minor influence on monetary losses and business interruption. Forecasts of structural damage to road infrastructure is determined to be based on flow velocity alone while the energy head is suggested as a suitable flood impact parameter for reliable forecasting of structural damage to residential buildings [3]. However, it is generally accepted that the higher the flow velocity of the floodwater, the greater the probability (and extent) of structural damage [4].

USACE [5] states that velocity is a major factor that could aggravate structural and content damage during flooding events. High velocities limit the time available for emergency measures and evacuation. The additional force of high velocities creates greater danger of foundation collapse and forceful destruction of contents [5]. For instance, Smith [6] states that a velocity of $3 \mathrm{~m} / \mathrm{s}$ acting over a $1 \mathrm{~m}$ depth will produce a force sufficient to exceed the design capacity of a typical residential wall. The study shows further critical combinations of water depth and flow velocities for building failure for three different residential building types. These range from above $0.5 \mathrm{~m}$ water depth and $4 \mathrm{~m} / \mathrm{s}$ flow velocities to above $3 \mathrm{~m}$ water depth with no flow velocity for single storey weatherboard buildings [6].

The study of dam-break flow is important in providing vital information needed for risk assessment and management of river valleys and coastal plains. Such information may include useful data on dam-break flow variables such as initial dam conditions, water depth downstream, flow velocity etc.

Moreover, physical modelling of dam-break waves is relatively limited. Most predictions on dam-break waves are often based upon numerical predictions, validated by limited data sets. According to Chanson [7] current knowledge of dam-break waves in dry channels remains rudimentary despite a few available studies.

In this paper, an experimental study of a dam-break flow is presented. Most existing studies about dam-break flows are focused on variables such as measurements of velocity profile and the water level using a Particle Tracking Velocimetry (PTV) algorithm and/or Particle Image Velocimetry (PIV) algorithm. However, in this study, an indirect way of measuring the flow 
velocity was applied. The present study developed simple methods for estimating instantaneous dam-break floodwater front velocity over the whole flow depth in a dry channel using image acquisition techniques. The main feature of this development is its simplicity that is well-suited to initial investigations.

\section{Dam-break velocity and Imaging System: an overview}

Ritter in 1892 was the first to investigate the dam break problem analytically [7]. His results have been used often for comparison of experimental and numerical data. Ritter derived the velocity of the positive wave front based on shallow water theory being twice the wave's celerity $c_{o}$ as:

$$
v_{F}=2 c_{o}=2 \sqrt{g H_{o}}
$$

where $H_{o}$ is the initial height of the reservoir.

Lauber and Hager [8] as well as Stansby et al. [9] have been known for carrying out recent experiments in the field of dam-break waves using digital image processing. Stansby et al. [9] compared their experimental data to Stoker's analytical solution. It was found that solving Stoker's equations for the positive wave front of dam-break waves on dry horizontal beds leads to the same constant front velocity as found by Ritter in eqn (1). Besides these investigations there had been very few experimental works on dam-break waves in smooth horizontal channels. This might be the result of high demand on measuring techniques which has to be provided for extremely unsteady and speedy flow.

Recently, a range of novel experimental methods based on signal and image analysis system have been developed for measuring flow velocities which are particularly useful in unsteady flows such as those generated in dam-break conditions. The data obtained can be used for the validation of numerical computations. The techniques involve the flow field being illuminated with a thin light sheet from a powerful source and might be filmed photographically or digitally.

According to Adrian [10] once several particles appear in the illuminated area, then the velocity vectors can be obtained for this area using tracking algorithm techniques based on auto-correlation, cross-correlation or Young's fringe method. A typical set-up represented a flow seeded with particles which could be imaged from above or through a transparent side-wall. The particles are roughly identical and should appear brighter than the surrounding fluid on the digital images.

The flow could be imaged from a single camera or from two cameras in a stereoscopic arrangement. When the imaged scene is immersed in a liquid and seen from the outside through a transparent wall, the image formation can be strongly influenced by refractive effects. Each interface separating materials of different refractive indexes will bend light rays according to Snell's law [11].

Using imaging systems to obtain quantitative velocity flow field information from particle movements encompasses a number of different methods depending on the form of the capture image and the analysis technique employed. The 
particle velocities are obtained as inter-frame displacements from the particle positions using various methods. Such methods include Particle Tracking Velocimetry (PTV), Particle Image Velocimetry (PIV) and Particle Streak Velocimetry (PSV). In all the techniques, the displacement of the particles within a field of view over a known period yields information about the velocity vector field simultaneously over the whole plane.

PTV requires individual particles to be located in an image and successive images to be recorded on successive frames and analyses pairs of single exposed digital images to produce whole field maps of velocity vectors. The distance travelled by an individual particle is then calculated and the velocity found knowing the time interval between images. Various correlation algorithms to allow the tracking of particles from frame to frame were described by Chegini et $a l$. [12] and Liem and Kongeter [13].

Also, the application of particle streak in fluid mechanics are often used for qualitative flow visualisation as illustrated by Van Dyke [14] but the images produced can be digitised for development into the quantitative measuring technique known as PSV. This method is often used when the medium fluid has a seeding particle concentration less than that for PTV and does not require individual streak images to be overlapped and distinguished from each other. As the individual streak lengths are determined and the exposure time is known, the velocity associated with the particle streak can be obtained.

The PIV system consists of different optical components. Particles in the fluid are illuminated in a plane by a light source. The light scattered by the particles is recorded by a camera on a sequence of frames. In PIV, the average velocity vectors are obtained for a cloud of particles based on image cross-correlation techniques whereas for PTV the individual particle motions are resolved and full sets of particle trajectories can be reconstructed by following the same particle over many successive frames [15]. Many investigators that have used PIV or its adaptations have employed the use of coloured droplets having specific gravities close to unity (e.g. a mixture of carbon tetrachloride, xylene and zinc oxide). The movements of these particles are then recorded on a cine film as waves pass down the channel. Frame-by-frame analysis of the motions of the particles allows the water-particle kinematics to be estimated. For further details on PIV, literature such as Raffel et al. [16] or Chegini [17] may be reviewed.

However, in this study, water-particle velocity measurements were made using a different adaptation of PIV. The time variations of the horizontal components of the front edge of the floodwater were traced and located at various positions from which the propagation velocities of the floodwater wave were obtained using appropriate combination of Newton's Equations of Motion.

\section{Experimental work}

This work was carried out in the Materials and Hydraulic Laboratory of the School of the Built Environment, Liverpool John Moores University. A Low Cost Wave Tank (LCWT) was primarily designed and constructed to simulate dam failure in order to generate floodwater waves. The main aim was to 
investigate the dissipation of energy of the floodwater waves in terms of impact pressures on newly designed seawall models. However, the preliminary experiments were conducted with a focus on the estimation of floodwater front velocity as well as the characterisation of the flow in the channel. The floodwater flow velocity is largely related to the impact pressures.

The test facility and the detailed laboratory arrangements are as shown in Figure 1 and Figure 2 respectively. A series of tests were performed in a $4.70 \mathrm{~m}$ long, $0.40 \mathrm{~m}$ wide, and $0.50 \mathrm{~m}$ deep wave tank. The length of the reservoir was $1.0 \mathrm{~m}$ while the propagating distance of the floodwater wave was $2.7 \mathrm{~m}$ (see Figure 2). One side of the channel as well as its base was made from plywood while the other side of the channel was made of clear Perspex which enabled optical measuring video footage of the whole process (see Figure 1). RCD protected lights were used in the process to improve visual observation and the quality of video footage. The flow was imaged by a strategically positioned camera through the side of the channel made of clear Perspex. A JVC TK $1085 \mathrm{E}$ high-speed digital camera was used, acquiring grey-scale images at a rate of 40 frames per second, with a resolution of 256 by 256 pixels.

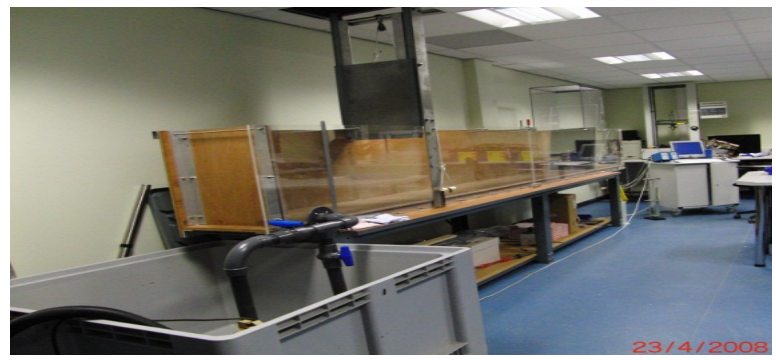

Figure 1: Instrumented Low Cost Wave Tank (ILCWT).

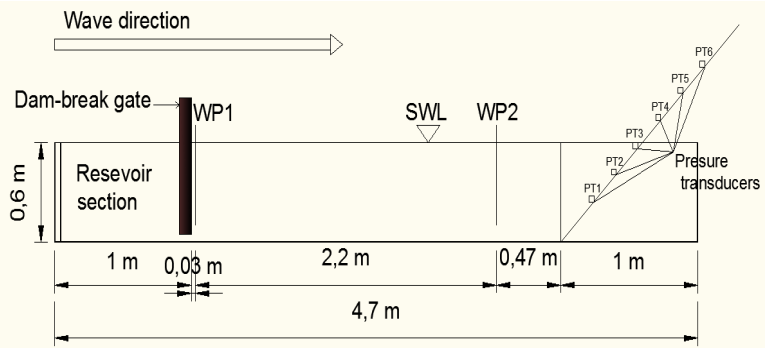

Figure 2: Experimental set-up.

With the gate initially in position to create a dam, an upward impulse is generated by releasing/pulling the rope through the pulley system. Tests were conducted with the downstream channel completely dry prior to experimentation, essentially modelling the dry beach common at urban waterfronts [7]. Experiments were also conducted with a wet-bed downstream at 
various ratios of upstream-downstream depths $\left(\mathrm{H}_{\mathrm{ds}} / \mathrm{H}_{\mathrm{us}}\right)$. Positive dam-break waves downstream were exclusively considered throughout the study. The initial levels of the water body within the reservoir were varied between $0.15 \mathrm{~m} \leq \mathrm{d}_{\mathrm{o}} \leq$ $0.55 \mathrm{~m}$.

For wet-bed downstream experiments, downstream depths $\left(\mathrm{H}_{\mathrm{ds}}\right)$ of $0.05 \mathrm{~m}$, $0.10 \mathrm{~m}$ and $0.15 \mathrm{~m}$ were investigated. Within the available experimental facilities any downstream depth higher than $0.15 \mathrm{~m}$ did not give appreciable outcomes. At the dead end, only the smooth surface wall model in vertical angle was chosen for the trial experiments and each run of initial reservoir depth was repeated five times to analyse the spread of data in terms of the time taken for the wave front to impact the wall.

Flow patterns of the floodwater in the channel were visualized and video footage recorded. The camera was strategically positioned to cover the entire flow area of interest. The flow period between the two locations of interest within the channel was obtained from the digitized image analysis. The movement of front water within this field of view was then analysed. However, the present study assumed the case by which the leading edge of floodwater is captured rather than the seeding method. Two different approaches were then used for the leading edge image capturing.

The first approach was by using the video system comparable to the PIV method referred to as the Imaging System (IS). The second approach involved using two suitably positioned wave probes (sensors) within the channel hence termed Sensor Signal Capture (SSC) technique (see Figure 2). For the SSC technique the two wave probes were placed at two different distances apart $(0.41 \mathrm{~m}$ and $2.2 \mathrm{~m}$ apart) to compare the results with that of the Imaging System. The time at which each wave probe received signal of the leading flow was deduced. Knowing the distance between the two wave probes, average front water flow velocity was calculated using an appropriate combination of equations.

For the IS, when the reservoir water depth $d_{o}=0.15 \mathrm{~m}$, propagation time obtained was, $t=2.08 \mathrm{~s}$, the propagation distance is a constant value and is given as, $S=2.7 \mathrm{~m}$ (see Figure 2). Hence, the rate of acceleration of wave front $a$, as well as the average floodwater front velocity $v$ was then computed using appropriate Newton's equations of motion.

\section{Results and discussions}

Using this approach interesting results were obtained in terms of the wave front velocity for dry-bed and wet-bed downstream conditions at varying reservoir depths. Figure 3 depicts the variation of the obtained floodwater front velocity against reservoir depth using the IS. The figure shows that the front velocity of the floodwater increases with increased reservoir depth. The correlation coefficient $\left(\mathrm{R}^{2}\right)$ is 0.9811 , indicating a strong relationship exists between the velocity and the initial depth of water in the reservoir section. This linear variation is expected from the analytical solution of one-dimensional frictionless and horizontal dam-break flow problem developed by Ritter in 1892 [7]. 
The results of the front velocity with dry-bed and wet-bed downstream conditions are shown in Table 1. Initial downstream water depths of $0.05 \mathrm{~m}$, $0.10 \mathrm{~m}$ and $0.15 \mathrm{~m}$ were investigated with varying initial reservoir depths and compared (Table 1). Figure 4 emphasizes that the velocity decreases as the downstream initial water depth increases. A dry-bed downstream gave some unexpected results in this case. Figure 4 as well as visual and video analysis also indicated that higher values and complexity of flow characteristics were obtained for the lower downstream water depth case than for the case with higher downstream water depths. Figure 4 also shows that the initial slope of the velocity variation decreases as the downstream initial water depth increases. For all depth ratios, the velocity profiles eventually became quite stable after the bore developed downstream which is considered to be satisfactory for the downstream subcritical flow region.

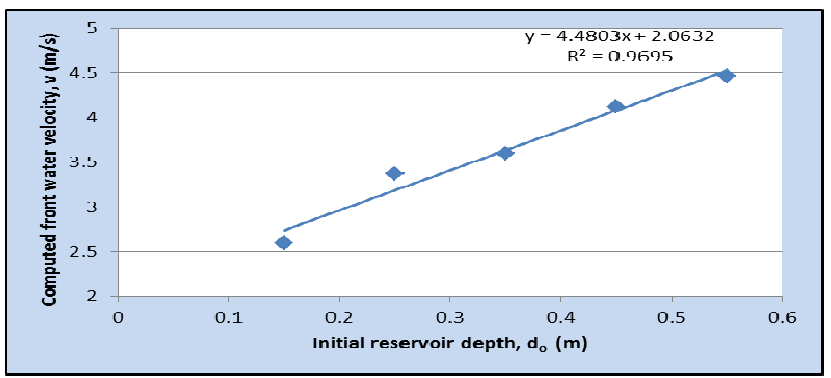

Figure 3: Variation of front water velocity with varying initial reservoir depths for a dry-bed downstream.

Table 1: Computed front water velocity for dry-bed and wet-bed downstream at varying reservoir depths.

\begin{tabular}{|c|l|l|l|l|}
\hline $\begin{array}{c}\text { Depth of } \\
\text { water in the } \\
\text { reservoir, } \mathrm{d}_{\mathrm{o}} \\
(\mathrm{m})\end{array}$ & $\begin{array}{c}\text { Velocity, v } \\
(\mathrm{dry}-\mathrm{bed}) \\
(\mathrm{m} / \mathrm{s})\end{array}$ & $\begin{array}{c}\text { Velocity, } \\
\left(\mathrm{H}_{\mathrm{ds}}=0.05 \mathrm{~m}\right) \\
(\mathrm{m} / \mathrm{s})\end{array}$ & $\begin{array}{c}\text { Velocity, v } \\
\left(\mathrm{H}_{\mathrm{ds}}=0.1 \mathrm{~m}\right) \\
(\mathrm{m} / \mathrm{s})\end{array}$ & $\begin{array}{c}\text { Velocity, v } \\
\left(\mathrm{H}_{\mathrm{ds}}=0.15 \mathrm{~m}\right) \\
(\mathrm{m} / \mathrm{s})\end{array}$ \\
\hline 0.15 & 2.5962 & 2.70 & 2.17 & 2.06 \\
\hline 0.25 & 3.3751 & 3.53 & 1.56 & 1.70 \\
\hline 0.35 & 3.6000 & 4.50 & 1.23 & 1.47 \\
\hline 0.45 & 4.1222 & 4.50 & 1.23 & 1.29 \\
\hline 0.55 & 4.4628 & 5.19 & 1.07 & 1.23 \\
\hline
\end{tabular}




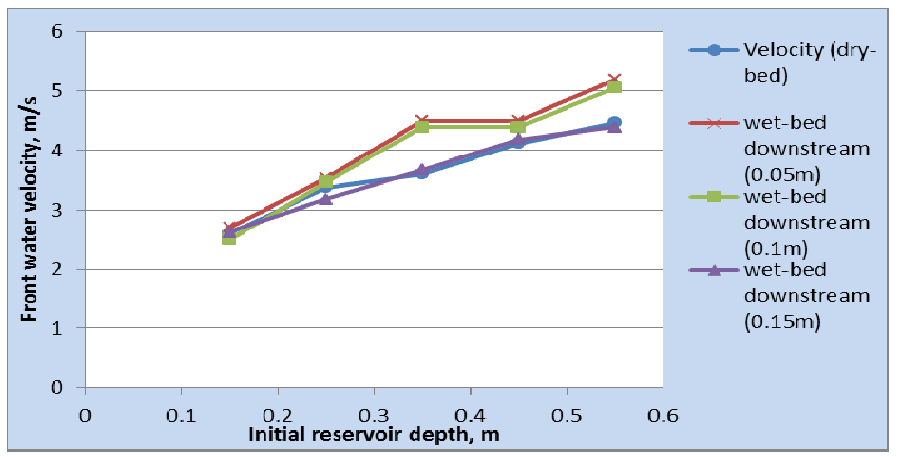

Figure 4: Comparison of the front water velocities for dry- bed and wet-bed at various initial water depths downstream.

The accuracy of the flow velocity relies on several factors. In the present experiment the flow velocity is mainly associated with the precision of the time interval between image pairs and the exactness of the displacement measurement. Thus, floodwater front velocity was again computed using the SSC technique described earlier to validate the reliability and accuracy of the IS. Figure 5 compares the results of the two methods. The results obtained using the two techniques indicated a good agreement with the dam-break wave theory however; it was observed that the velocities obtained using the SSC method with wave probes at a shorter distance away from each other $(0.41 \mathrm{~m}$ apart $)$ appeared to be closer in agreement to that obtained using IS (Figure 5). This result follows Chegini [17] concept that this distance needs to be small enough to maintain a degree of correlation and accuracy in the measurements of floodwater propagation velocity.

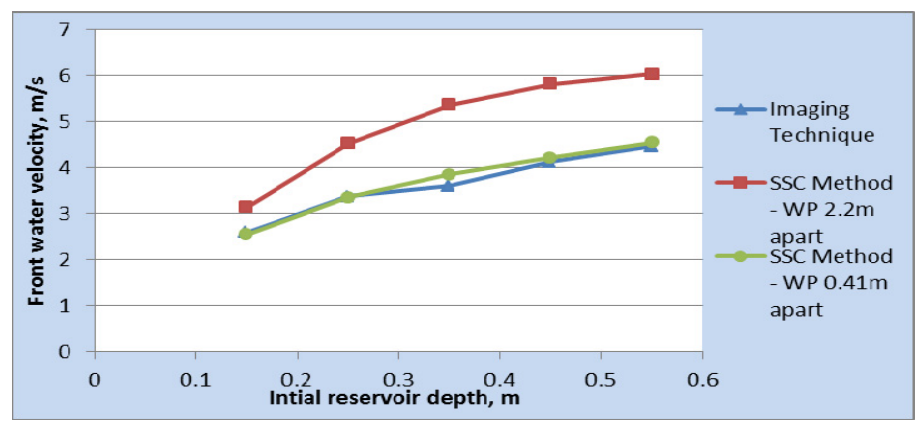

Figure 5: Comparison of the computed front water velocity using various methods for dry-bed downstream conditions. 
Some previous investigators interchanged wave celerity with front water flow velocity. This concept is verified in the present study. An approximation of wave celerity was obtained from the shallow water relationship taken as:

$$
C=\sqrt{g d_{o}} \text { (as a first order approximation) }
$$

where $C$ = wave celerity, $g=$ gravity acceleration and $d=$ initial reservoir water depth.

The solitary wave theory gives celerity for the steep waves as:

$$
C=\left(g d\left(1+\frac{H}{d}\right)\right)^{\frac{1}{2}}
$$

where $H=$ water depth in the channel and $d=$ water surface elevation from Still Water Level (SWL).

However, considering the dry-bed downstream condition, eqn (3) is simplified to the form of shallow water relationship equivalent to eqn (2). This allows the use of eqn (3) to compute floodwater wave celerity for the present experiments. Also, using the empirical and analytical equations for the flow velocities proposed by various previous investigators, the velocities obtained from their models are compared with the celerity of the present study. It can be seen from Figure 6 that the flow celerity of the present study is in close agreement with the front water velocity of Lauber and Hager [8] while other investigators appeared to overestimate the front water velocity in relation to celerity of the flow.

Similarly, Figure 7 compares the front water flow velocity of previous investigators with the floodwater front velocity obtained in the present study. It

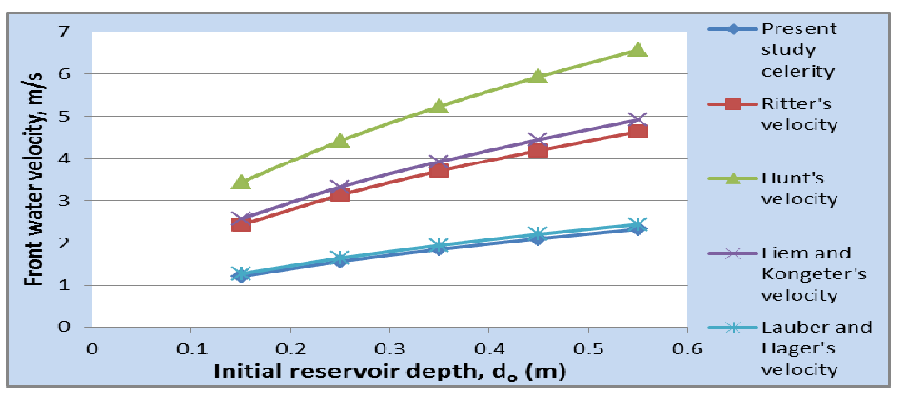

Figure 6: Comparison of floodwater front velocity of existing theories with the flow celerity of the present study. 


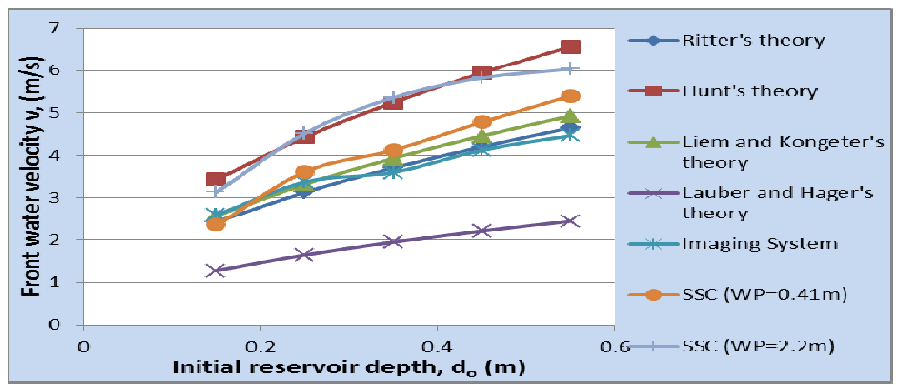

Figure 7: Comparison of the computed front water velocities for this study with various existing theories.

can again be seen from the figure that the front water velocity computed using SSC method with wave probes $0.41 \mathrm{~m}$ apart and that of IS are in close agreement with Liem and Kongeter's theory [13] as well as with Ritter's predictions [7]. Hunt's theory has fair agreement with front water velocity computed using SSC method with wave probes of $2.2 \mathrm{~m}$ apart. It should be noted that a comparison with Hunt's theory may be incorrect at the upstream end of the channel since Hunt's equation is said to be valid only once the wave front has travelled a distance of more than 4 times the reservoir length [18].

\section{Conclusions}

The use of digital imaging for qualitative and quantitative characterisation of fluid flows is not new. In recent years however, with the rapid development of powerful digital cameras at affordable prices and the advances in robust and fast image processing techniques, this tool has become very popular.

In the present study, propagation velocities of floodwater flow have been computed in an idealized dam-break problem using various adaptations of the commonly used PIV method. The IS and the SSC methods described in section 3 have been adopted. The results obtained using the two techniques demonstrated good agreement with the dam-break wave theory. However, it was observed that the velocities obtained using the SSC method with wave probes at shorter distance away from each other $(0.41 \mathrm{~m}$ apart $)$ appeared closer in agreement to the IS than that of the SSC with $2.2 \mathrm{~m}$ separation. In addition, it is also indicated that the propagation velocity obtained using the SSC method with wave probes $0.41 \mathrm{~m}$ apart and that of the IS appeared in close agreement with some previous researchers, particularly Chegini's concept [17].

It was also revealed that most previous investigators over-estimated front water velocity by interchanging it for the wave celerity which implies that caution should be taken when doing this as it is only applicable in certain circumstances. Furthermore, the results of comparison of front velocity with various downstream water levels (DSWL) revealed that higher DSWL reduces the speed of the bore, which indicates that the water in front of the travelling bore reduces the speed of the flood wave. More importantly, this development 
represents a useful laboratory scheme for analysing hydrodynamics model studies and is well suited for initial investigations.

\section{References}

[1] Sayers, P., Hall, J., Dawson, R., Rosu, C., Chatterton, J. and Deakin, R., Risk Assessment of Flood and coastal Defences for strategic Planning (RASP) - A high level Methodology. DEFRA Conference of Coastal and River Engineers, Keele University, HR Wallingford, 2002.

[2] Kelman, I. and Spence, R., An overview of flood actions on buildings. Eng. Geol., 73, pp. 297-309, 2004.

[3] Kreibich, H., Piroth, K., Seifert, H., Maiwald, H., Kunert, U., Schwartz, J., Merz, B. and Thieken, A. H., Is flow velocity a significant parameter in flood damage modelling? Natural Hazards Earth System Science, 9, pp. 1679-1692, 2009.

[4] Soetanto, R. and Proverbs, D. G., Impact of flood characteristics on damage caused to UK domestic properties: the perceptions of building surveyors. Structural Survey, 22 (2), pp. 95-104, 2004.

[5] USACE, Design of Revetments, Seawalls and Bulkheads. EM $1110-2$ 1614, 1996.

[6] Smith, D. I., Flood damage estimation - A review of urban stage damage curves and loss functions. Water SA, 20 (3), pp. 231-238, 1994.

[7] Chanson, H., Applications of the Saint-Venant Equations and method of Characteristics to the Dam Break Wave Problem. Hydraulic Model Reports of Department of Civil Engineering, University of Queensland, Report No. CH55/05, ISBN 1864997966, 2005.

[8] Lauber, G. and Hager, W. H., Experiments to dam-break waves: Horizontal channel. Journal of Hydraulic Research, 36 (3), pp. 291-307, 1998.

[9] Stansby, P. K., Chegini, A. H. N. and Barnes, T. C. D., The initial stages of dam-break flow. Journal of Fluid Mechanics, 374, pp. 407-424, 1998.

[10] Adrian, R., Engineering Application of Particle Image Velocimeters. Proc. of ICALOE, Laser Institute of America, pp. 56-71, 1989.

[11] Douxchamps, D., Spinewine, B., Capart, H., Zech, Y. and Macq, B., Particle-Based Imaging Methods for the Characterisation of Complex Fluid Flows. Proc. of the IEEE Oceans, pp. 20-25, 2004.

[12] Chegini, A. H. N., Pender, G., Slaouti, A. and Tait, S. J., Velocity measurement in dam-break flow using imaging system. Proc. Of the 2nd Int. Conf. On Fluvial Hydraulics, IAHR/AIRH, 2 (June), pp. 858-867, 2004.

[13] Liem, R. and Kongeter, J., Application of High-Speed Digital Image Processing to Experiments on Dam Break Waves. Proc. of Concerted Action on Dam-Break Modelling (CADAM) Conference, European Community Workgroup, pp. 399-411, 1999.

[14] Van Dyke, M., An Album of Fluid Motion, Publication of Parabolic Press, 1982. 
[15] Capart, H., Young, D. L. and Zech, Y., Voronoi imaging methods for the measurements of regular flows. Experimental Fluids, 32, pp. 121-135, 2002.

[16] Raffel, M., Willert, C. E. and Kompenhaus, J., Particle Image Velocimetry - A Practical Guide. Springer-Verlag: Berlin and New York, 1998.

[17] Chegini, A., Fundamental Investigations of Dam-break Flows. Ph.D. Thesis, Department of Civil Engineering, University of Manchester, Manchester, UK, 1997.

[18] Hunt, B., Dam-break solution. Journal of Hydraulic Engineering, ASCE, 110 (6), pp. 675-686, 1984. 